
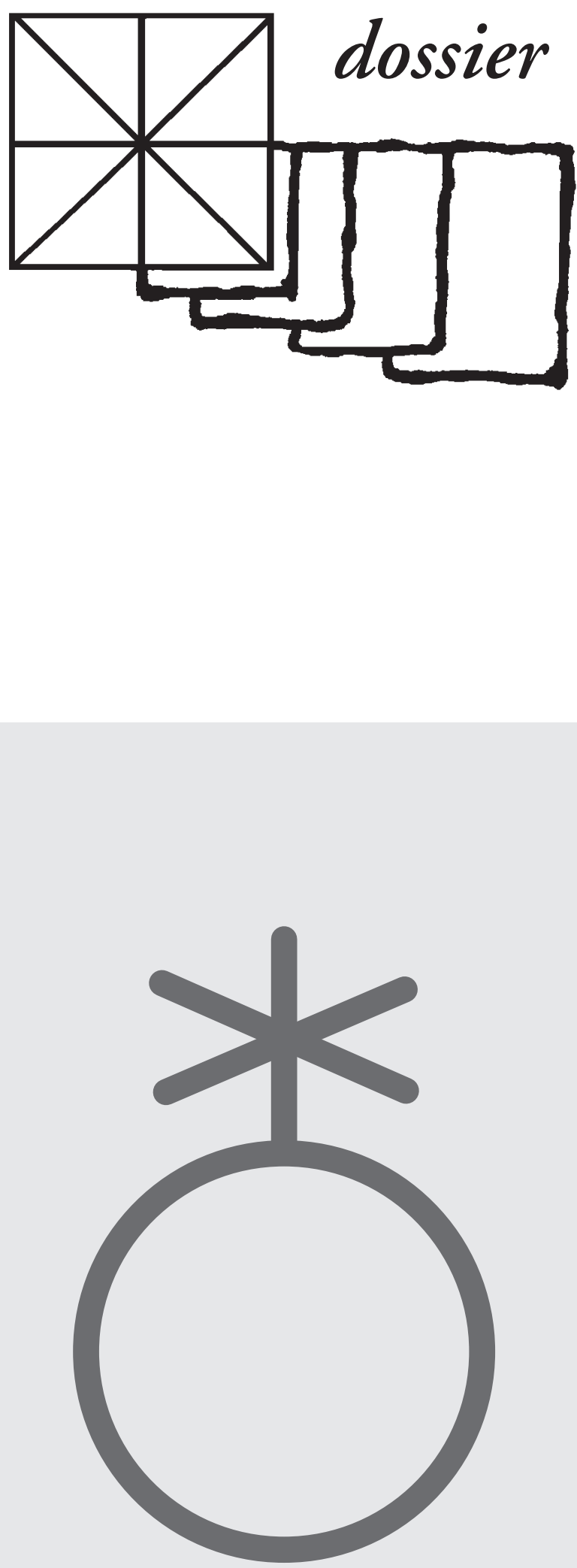


\section{IDENTIDADES TRANS Y NO BINARIAS. DESDE LA CLÍNICA A LAS NEUROCIENCIAS}

La llamada por algunos "ciencia de lo sexual", y luego Sexología se constituyó como campo de conocimientos específicos, hacia fines del siglo XIX, a partir de la obra de tres médicos psiquiatras: Richard von Krafft-Ebing (1840-1902), sucesor de Theodor Meynert en la cátedra de la Universidad de Viena y autor del famoso texto Psychopatia Sexualis, en 1886; Albert Moll (1826-1939) especialista de la sugestión y discípulo de Hippolyte Bernheim en Nancy, quien se hizo célebre con la publicación de su libro Untersuchugenüber die Libido sexuales y Henry Havelock Ellis (1859-1939) autor, a partir de 1897, de los ocho volúmenes de sus influyentes Studies in the Psychology of Sex.

Pocos años después, en su difundido texto Tres ensayos sobre la teoría sexual, publicado en 1905, Sigmund Freud reconoció su deuda con los sexólogos. Pero, a diferencia de aquellos que la entendían como una disciplina vinculada a la biología, cuyo objeto de estudio era la actividad sexual humana y su tratamiento, Freud elabora una teoría universal de la sexualidad fundándola sobre la noción de libido, distinguiendo teóricamente su doctrina de toda forma de estudio comportamental.

En la psiquiatría, desde finales del siglo XIX, diversos autores comenzaron a interesarse en el tema. En ese contexto fueron introducidos en el lenguaje lego dos neologismos: "heterosexual", en 1868, y "homosexual" en 1869.
El introductor de ambos términos fue Karl-Maria Kertbeny (1824-1882), escritor, poeta y patriota húngaro. El suicidio de uno de sus amigos de juventud al ser chantajeado por su condición de homosexual produjo una viva impresión en Kertbeny, y lo impulsó a enrolarse en una activa defensa de los derechos del hombre, en particular de los derechos de los homosexuales, ya que sostenía que las leyes en contra de la homosexualidad eran contrarias a los derechos del hombre y que los actos sexuales privados libremente consentidos no debían tener relevancia penal. Para sostener su posición publicó numerosos panfletos y ensayos en contra del artículo 143 del Código Penal prusiano, que castigaba la homosexualidad, y cuyo espíritu punitivo pervivió en el artículo 175 del Código Penal alemán.

Entre los argumentos de los que fue un precursor se encuentra, por ejemplo, su defensa de la homosexualidad como un estado innato, no modificable y permanente de las personas; opinión opuesta a la idea dominante en la época, que consideraba la homosexualidad como un vicio.

En 1878 Kertbeny contribuyó con un capítulo sobre la homosexualidad en la obra Die Entdeckung der Seele ("El descubrimiento del alma") de Gustav Jäger. Si bien el capitulo fue rechazado por el editor por encontrarlo excesivamente polémico, Jäger asumió la terminología de Kertenby y la utilizó en el resto de la obra. Lo mismo hizo Krafft-Ebing quien la introdujo en el lenguaje psiquiátrico en su Psychopathia 
Sexualis de 1886, popularizando así los términos "homosexual" que remplazó a las palabras en curso hasta ese momento: uranista, sodomita, invertido; $y$ "heterosexual", que rápidamente cobró difusión para clasificar a las personas sobre la base de la identidad anatómica del partenaire en el acto sexual.

Sin embargo, esa dicotomía simplista dejaba mucho de lo humano fuera de ella o en las sombras. En efecto, en sus estudios históricos Jonathan Ned Katz, autor, entre otras obras del género, de La invención de la heterosexualidad, publicado en 1995, demostró la complejidad del puzzle que estos términos permitieron simplificar.

Luego de la Primera Guerra mundial la sexología tomó un cariz político centrado sobre las ideas de la revolución sexual, y en los años posteriores a la Segunda Guerra Mundial cobró un desarrollo considerable a partir de los EE. UU. El informe elaborado por Albert Kinsey sobre la sexualidad de los hombres y mujeres norteamericanos, publicado entre 1948 y 1953, y los trabajos de William Masters y Virginia Jonson contribuyeron ampliamente a desencadenar ese fenómeno. En las décadas posteriores se asistió al desarrollo de la sexología como disciplina clínica alcanzando una gran audiencia entre el público en general.

De 1870 a 1940 se produjo en la sociedad civil, particularmente en Alemania, una serie de sucesos que conmovieron la percepción social sobre la sexualidad. En efecto, al calor de las luchas por la derogación del artículo 175 del código penal alemán y el proceso judicial a Oscar Wilde, Magnus Hirschfeld, Max Spohr, Eduard Obergy y Franz Joseph von Bülow fundaron en Berlin el Wissenschaftlich-humanitäres Komitee (Comité Científico Humanitario), primera organización homo- sexual del mundo y se inició el llamado primer movimiento homosexual, un cambio a partir del cual se desarrolló el movimiento de liberación LGBT o Movimiento por una libre orientación sexual contemporáneo, que tuvo su comienzo formal en 1969 con la manifestación convocada a consecuencia de los acontecimientos acaecidos en un bar gay llamado Stonewall en Nueva York, y cuyo impetuoso desarrollo llega hasta hoy.

Sin embargo, como decíamos en un número anterior de Vertex "... a pesar de todo lo dicho, lo escrito y lo debatido sobre sexualidad humana desde las épocas iniciales de Freud hasta nuestros días, sorprende una vez más encontrarse cara a cara con las sordas resistencias que esta apasionante temática genera. Es que la sexualidad humana, tan omnipresente como escurridi$z a$, tan universal y evidente como individual e intransferible, no se deja dominar con facilidad. Tal vez la dificultad primera resida en el hecho, no por ya sabido menos problemático, de que quien habla de sexualidad no puede dejar de hablar sobre sí mismo de una manera o de otra. No existe un solo párrafo escrito sobre la materia que no nos aluda a cada uno de nosotros, que no nos interpele como seres necesaria e inevitablemente atravesados por esta experiencia histórica, fundante, y a la vez permanentemente actual. Los médicos, inclusive los psiquiatras, nos tropezamos con dificultades toda vez que debemos abordar temáticas que no sólo afectan a nuestros pacientes sino que nos aluden a nosotros mismos como seres humanos"; y señalábamos que una Sexología actualizada, iluminada por la subjetividad contemporánea, no ha entrado adecuadamente en la curricula de los estudios médicos.

Los artículos del presente Dossier invitan a la reflexión y brindan información fundada sobre varios tópicos relativos a esta problemática que atraviesa la clínica cotidianamente. 